\title{
Cyclin D2 Is Critical for Intermediate Progenitor Cell Proliferation in the Embryonic Cortex
}

\author{
Sara B. Glickstein, ${ }^{1}$ Julie A. Monaghan, ${ }^{2}$ Hajira B. Koeller, ${ }^{1,2}$ Tiffanie K. Jones, ${ }^{3}$ and M. Elizabeth Ross ${ }^{1,2}$ \\ ${ }^{1}$ Department of Neurology and Neuroscience and ${ }^{2}$ Graduate Program in Neuroscience, Weill Medical College of Cornell University, New York, New York \\ 10021, and ${ }^{3}$ Yale University, School of Medicine, New Haven, Connecticut 06510
}

Expression of cyclins D1 (cD1) and D2 (cD2) in ventricular zone and subventricular zone (SVZ), respectively, suggests that a switch to cD2 could be a requisite step in the generation of cortical intermediate progenitor cells (IPCs). However, direct evidence is lacking. Here, $\mathrm{cD} 1$ or $\mathrm{cD} 2$ was seen to colabel subsets of Pax6-expressing radial glial cells (RGCs), whereas only cD2 colabeled with Tbr2. Loss of IPCs in $c D 2^{-/-}$embryonic cortex and analysis of expression patterns in mutant embryos lacking $\mathrm{CD} 2$ or Tbr2 indicate that $\mathrm{cD} 2$ is used as progenitors transition from RGCs to IPCs and is important for the expansion of the IPC pool. This was further supported by the laminar thinning, microcephaly, and selective reduction in the cortical SVZ population in the $c D 2^{-1-}$ cortex. Cell cycle dynamics between embryonic day 14-16 in knock-out lines showed preserved parameters in cD1 mutants that induced cD2 expression, but absence of cD2 was not compensated by $\mathrm{cD} 1$. Loss of $\mathrm{cD} 2$ was associated with reduced proliferation and enhanced cell cycle exit in embryonic cortical progenitors, indicating a crucial role of $\mathrm{cD} 2$ for the support of cortical IPC divisions. In addition, knock-out of cD2, but not cD1, affected both $\mathrm{G}_{1}$-phase and also S-phase duration, implicating the importance of these phases for division cycles that expand the progenitor pool. That $\mathrm{cD} 2$ was the predominant D-cyclin expressed in the human SVZ at 19-20 weeks gestation indicated the evolutionary importance of cD2 in larger mammals for whom expansive intermediate progenitor divisions are thought to enable generation of larger, convoluted, cerebral cortices.

\section{Introduction}

The cerebral cortex arises through a precisely timed and orchestrated series of cell divisions to generate an astonishing array of neuronal and glial cell types, ordered in a highly stereotyped laminar organization (Takahashi et al., 1995a; Caviness et al., 2003; Tarui et al., 2005). Not only does progenitor proliferation set the size of the cerebral cortex, but it also determines cortical morphogenesis, whether brain contours will be smooth or convoluted, and whether the cerebral ventricles will be large or small (Chenn and Walsh, 2003; Kriegstein et al., 2006). Cortical divisions are subject to external factors and intrinsically programmed transcriptional subroutines that impact proliferation behavior of neural progenitors in a determination-stage-specific manner (Noctor et al., 2004, 2008; Englund et al., 2005; Hevner et al., 2006; Shen et al., 2006).

The cortical germinal epithelium was once considered relatively homogeneous, with neurogenesis occurring in the pseudostratified ventricular zone (VZ) and gliogenesis in the later arising subventricular zone (SVZ) or secondary proliferative

\footnotetext{
Received May 14, 2009; revised June 19, 2009; accepted June 24, 2009.

This work was supported by National Institutes of Health Grant P01NS048120 (M.E.R.). We are indebted to Dr. Chai-An Mao and Dr. William Klein (University of Texas, M. D. Anderson Cancer Center, Houston, TX) for generously providing fixed embryo brains from Tbr2fx/+::Foxg1-Cre $\times$ Tbr2fx/fx intercrosses used in this study.

Correspondence should be addressed to Dr. M. Elizabeth Ross, Department of Neurology and Neuroscience, Weill Medical College of Cornell University, 1300 York Avenue, Box 239, New York, NY 10065. E-mail: mer2005@med.cornell.edu.

S. B.Glickstein's present address: 16733 NE 41st Street, Redmond, WA 98052. E-mail:saraglickstein@gmail.com D01:10.1523/JNEUROSCI.2284-09.2009

Copyright $\odot 2009$ Society for Neuroscience $\quad 0270-6474 / 09 / 299614-11 \$ 15.00 / 0$
}

population (Levison and Goldman, 1993; Takahashi et al., 1995b). It has since been established that neurons may arise from either the VZ or SVZ, from asymmetric neurogenic divisions (primarily in the VZ) that yield a neuronal daughter and a replenished progenitor, or from symmetric neurogenic divisions (primarily in the SVZ) in which both daughters are neurons (Noctor et al., 2008). Thus, the prevailing outcomes of cytokinesis in the VZ (asymmetric daughter cells) and SVZ (symmetric daughter cells) suggest differences in the molecular machinery implementing these divisions.

We showed that two $\mathrm{G}_{1}$-phase active cyclins, cyclin D1 (cD1) and cyclin D2 (cD2), are differentially expressed in neural progenitor cells of the VZ (cD1) and SVZ (cD2) (Glickstein et al., $2007 a, b)$. Absence of either cyclin is associated with different histogenetic outcomes. Mice lacking cD2 are microcephalic despite normal body mass and parvalbumin-expressing interneurons are disproportionately missing in cerebellum and cerebral cortex (Huard et al., 1999; Glickstein et al., 2007b). In contrast, mice lacking CD1 are runted, but brain size is essentially normal, with no selective deficits in specific neuronal subsets (Chen et al., 2005; Glickstein et al., 2007b; and present study). Although cD2 expression in the SVZ cells suggested that $\mathrm{CD} 2$ may be important for the establishment of intermediate progenitors (Glickstein et al., 2007a), there is no direct evidence that $\mathrm{cD} 2$ is indeed expressed in transit amplifying progenitors or indication of its impact on cycling in either cortex or ganglionic eminence populations. Here, the relationships between $\mathrm{cD} 1$ or $\mathrm{cD} 2$ protein expression and radial glial cells (RGCs) or intermediate progenitor cells (IPCs) are explored. The data indicate that $\mathrm{cD} 2$ is criti- 


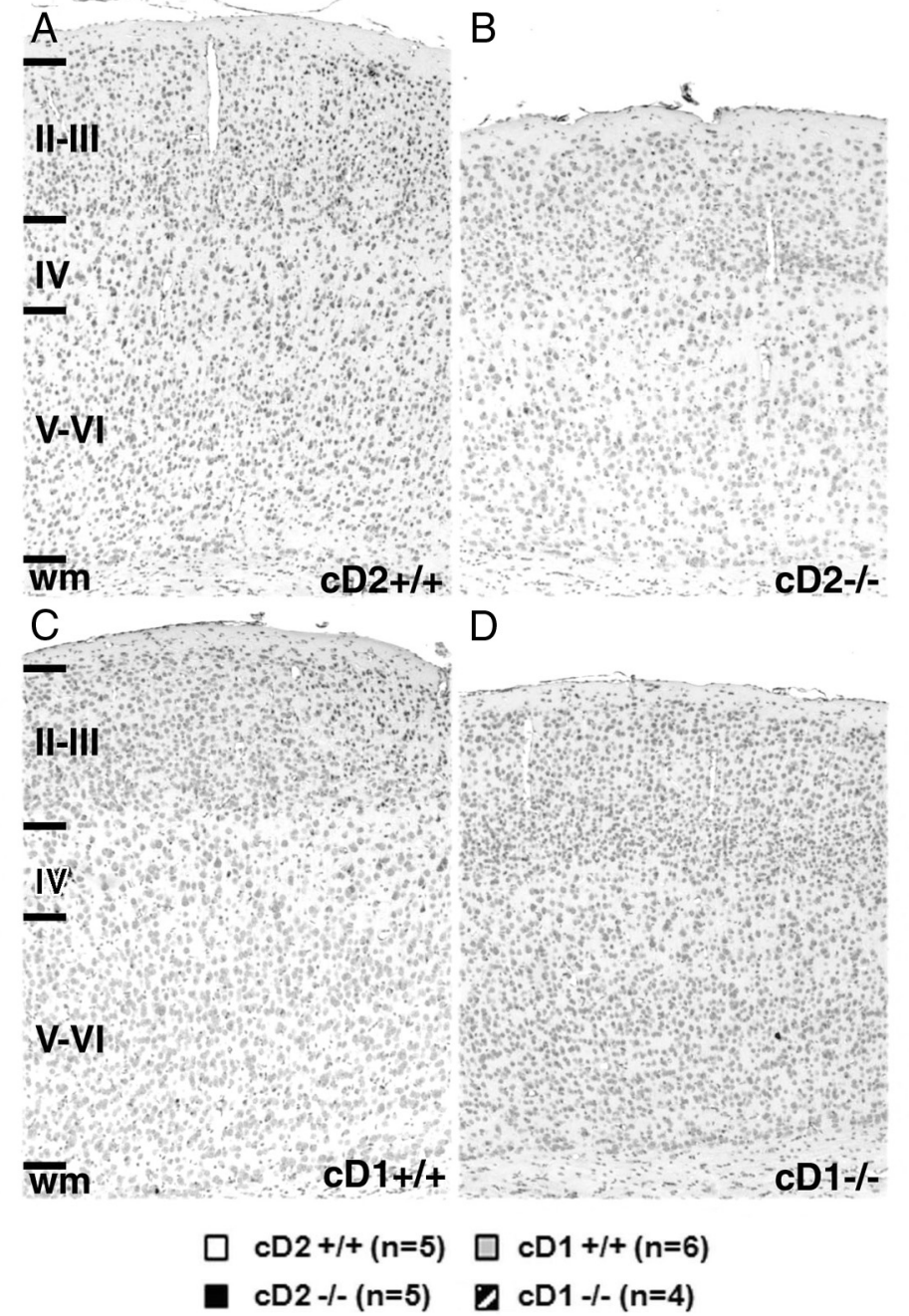

$\mathrm{E}$

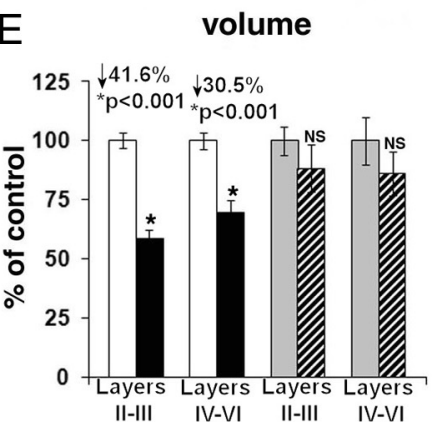

$\mathrm{F}$

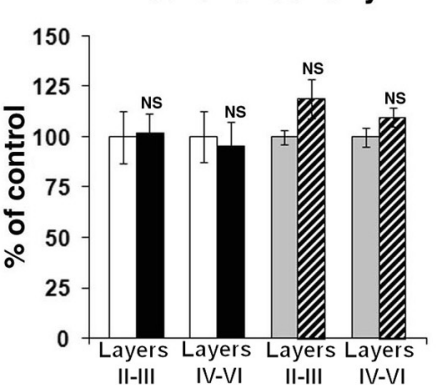

Figure 1. Cortical volume and neuronal density in the somatosensory barrel field cortex of $C D 2^{-1-}, C D 1^{-1-}$, and wild-type mice. $\boldsymbol{A}-\boldsymbol{D}$, Nissl-stained sections $(10 \mu \mathrm{m})$ show decreased cortical thickness in both superficial (II-III) and deep (IV-VI) layers of 8-week-old $C D 2^{-/-}(B)$ compared with littermate $\mathrm{CD2}^{+/+}(\boldsymbol{A})$. Cortical thickness of 3-week-old $C D 1^{-/-}(\boldsymbol{D})$ is only slightly reduced compared with littermate $C D 1^{+/+}(C)$. E S Somatosensory cortical volume is significantly reduced in $\mathrm{CD2}^{-/-}$compared with $C D 2^{+/+}$(layers $\mathrm{II}-\mathrm{III}>\mathrm{IV}-\mathrm{VI}$ ) and unchanged in $\mathrm{CD1^{-/- }}$ relative to $\mathrm{CD}^{+/+}$mice. $\boldsymbol{F}$, Neuronal density is unchanged in $\mathrm{CD}^{-/-}$compared with $\mathrm{CD2}^{+/+}$cortex despite reduced volume and is mildly and nonsignificantly increased in $\mathrm{CD}^{-/-}$relative to $\mathrm{CD}^{+/+}$. Volumes and densities in $C D 2^{-/-}$and $C D 1^{-/-}$are expressed as percentage of control $\left(\mathrm{CD} 2^{+/+}\right.$and $C D 1^{+/+}$, respectively; mean $\pm \mathrm{SEM})$. wm, White matter.

cally important for establishing a full complement of IPCs, whereas $\mathrm{CD} 1$ expression is not found in this expansive population. cD2 deficiency alters cell cycle parameters in the VZ, primarily affecting $\mathrm{G}_{1}$ - and $\mathrm{S}$-phases, but $\mathrm{cD} 1$ deficiency leaves cell cycle measures unchanged. Thus, $\mathrm{cD} 2$ is a major determinant of brain size and is more essential than $\mathrm{CD} 1$ because of the ability of $\mathrm{cD} 2$ to promote amplifying divisions.

\section{Materials and Methods}

\section{Animals}

Mice were housed in climate-controlled Thoren units with a $12 \mathrm{~h}$ light/dark cycle. The cD2 gene was inactivated by disruption of exons I and II (Sicinski et al., 1996). The cD1 gene was inactivated by the deletion of exons I-III (Sicinski et al., 1995). Heterozygous $c D 1^{+/-}$ and $c D 2^{+/-}$mice, maintained on a congenic C57BL/6J background, were bred to produce wild-type (WT) and homozygous null littermates for all studies. Tbr2 was conditionally inactivated in cortex starting at embryonic day 9.5 (E9.5) by Foxg1-Cre-mediated excision of Tbr2 exon 3 that was flanked by loxP (fx) sites (Sessa et al., 2008). Tbr2fx/+::Foxg1-Cre and $\mathrm{Tbr} 2 \mathrm{fx} / \mathrm{fx}$ mice were mated to produce Tbr2fx/fx::Foxg1-Cre conditional knock-out (CKO) and Tbr2fx/fx control sibling embryos harvested at E13 and E14.5 (kindly provided by C.-A. Mao and W. Klein, University of Texas, M. D. Anderson Cancer Center, Houston, TX). All procedures involving animals were performed in accordance with the National Institutes of Health Guide for the Care and Use of Laboratory Animals and were approved by the Institutional Animal Care and Use Committee.

\section{Genotyping}

Genomic DNA was extracted from tail snips using standard protocols and examined by PCRbased genotyping using primers for WT and null alleles as published previously (Sicinski et al., 1995, 1996; Sessa et al., 2008).

\section{Human tissues}

Fetal brain tissue was obtained from the National Institute of Child Health and Human Development Brain and Tissue Bank for Developmental Disorders under contracts N01HD-4-3368 and N01-HD-4-3383. Tissue was collected with proper consent and with the approval of ethics committees. There was no evidence of disease or developmental abnormality. Samples $(n=2)$ were obtained from Caucasian males at 19 and 20 gestational weeks after postmortem intervals of 1 and $4 \mathrm{~h}$, respectively, and storage for 11-12 years. Tissues were paraffinized, coronally sectioned $(10 \mu \mathrm{m})$, and immunostained as described below for mouse tissues.

\section{Immunohistochemistry}

Adult animals were anesthetized with ketamine/xylazine and perfused transcardially with $4 \%$ paraformaldehyde (PFA) in $0.1 \mathrm{M}$ phosphate buffer, $\mathrm{pH}$ 7.4. Embryo heads were drop fixed in $4 \%$ PFA overnight at $4^{\circ} \mathrm{C}$. Brains tissues were processed (Tissue Tech 2000; Bayer Corp.) for paraffin embedding in the coronal plane. Brains were sectioned at 4-10 $\mu \mathrm{m}$ (embryo to adult), mounted on adhesivecoated capillary gap slides (Thermo Fisher Scientific), and immunostained on a TechMate 500 semiautomated stainer (Ventana Medical Systems) after antigen retrieval by steam in Reveal buffer, pH 5.9 (Biocare Medical) for $30 \mathrm{~min}$ and cooling for $10 \mathrm{~min}$. Sections were treated with $3 \% \mathrm{H}_{2} \mathrm{O}_{2}$ for $10 \mathrm{~min}$, blocked in Sniper (Biocare Medical) for $30 \mathrm{~min}$, and then incubated with primary antibody overnight at $+4^{\circ} \mathrm{C}$. Sections were then sequentially incubated in species/isotype-appropriate second- 

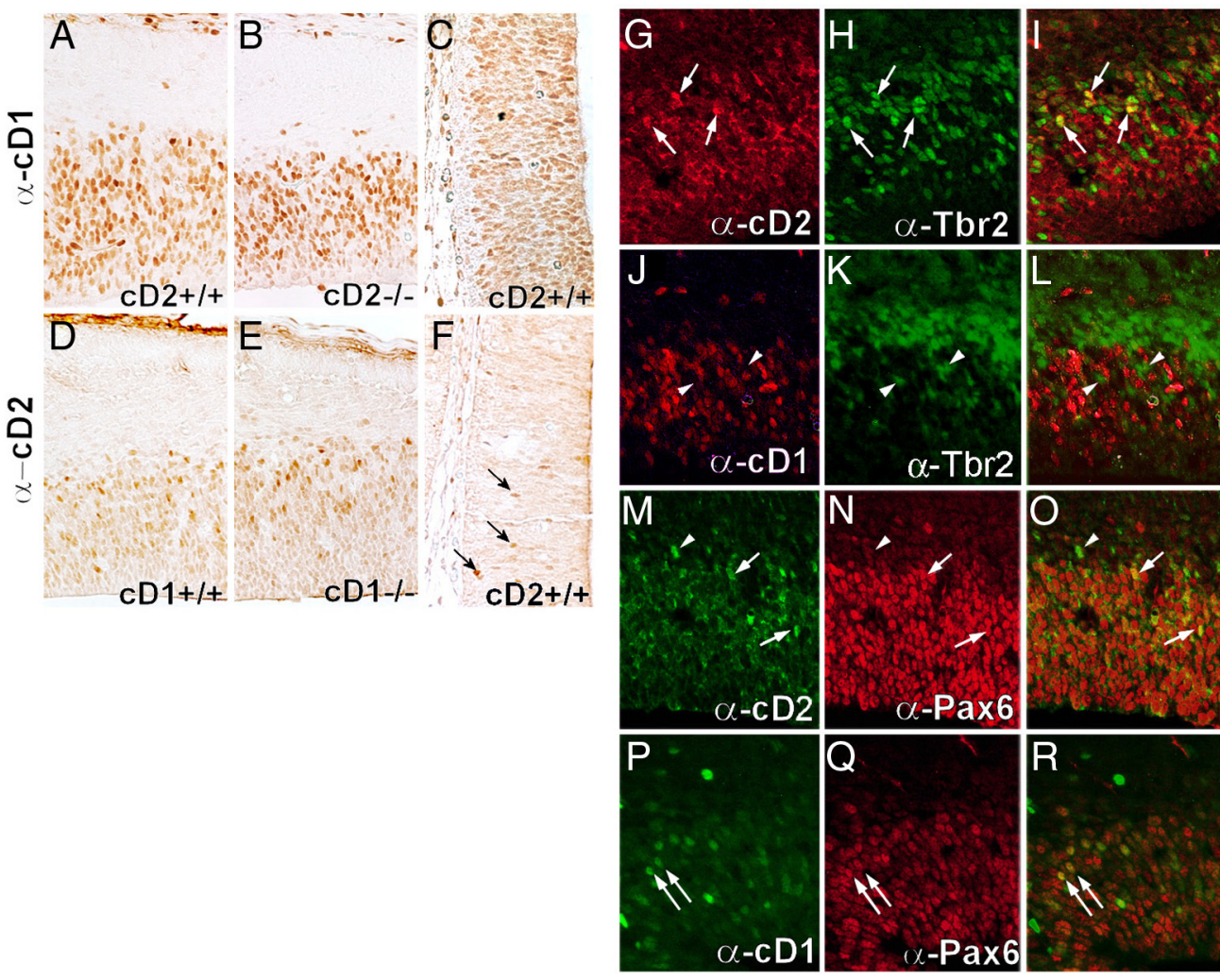

Figure 2. The expression of $\mathrm{CD2}$ is characteristic of intermediate progenitor cells in the cortex. $A-C, C D 1$-immunolabeled cells are predominantly in the VZ in the dorsomedial cortex (at mid-hemisphere) in WT mice at E14.5 (A, C). CD1 labeling in the SVZ and near the ventricular wall is reduced in $\mathrm{CD2}^{-/-}$mice $(\boldsymbol{B})$ compared with $C D 2^{+/+}(\boldsymbol{A})$. $\mathrm{CD1}$ immunolabeling is abundant in the rostromedial cortex of $C D 2^{+/+}$mice $\left(\boldsymbol{C}\right.$. $\boldsymbol{D}-\boldsymbol{F}$, Labeling for $\mathrm{CD} 2$ is restricted to abventricular regions of dorsomedial cortical proliferative zone in $C D 1^{+/+}(\boldsymbol{D})$ and $C D 1^{-/-}(\boldsymbol{E})$ mice and is just detectable in $\mathrm{CD}^{+/+}$rostromedial (cingulate) cortex $(\boldsymbol{F})$, in which the $\mathrm{SVZ}$ is less prominent at this age. Arrows identify $(D 2$-immunopositive nuclei in the adjacent septal cortex. $\mathbf{G}-\mathbf{L}$, The expression of $\mathrm{CD2}(\boldsymbol{G})$ and Tbr2 $(\boldsymbol{H})$ overlap $(\boldsymbol{I})$ in many nuclei in the cortex. However, $\mathrm{CD1}(\boldsymbol{J})$ and Tbr2 $(\boldsymbol{K})$ immunolabeling mark different nuclei $(\boldsymbol{L})$. $\boldsymbol{M}-\boldsymbol{R}$, The expression of $\mathrm{CD2}(\boldsymbol{M})$ or $\mathrm{CD1}(\boldsymbol{P})$ and $\operatorname{Pax6}(\boldsymbol{N}, \mathbf{Q})$ overlap $(\boldsymbol{O}, \boldsymbol{R})$. Arrows identify nuclei that coexpress markers, and arrowheads denote non-colabeled cells.

ary antibody and peroxidase-conjugated tertiary antibody (Signet Rabbit or Murine kit; Covance) or Vectastain Elite kit (Vector Laboratories) for $30 \mathrm{~min}$ each, followed by reaction with 3,3-diaminobenzidine (DAB) (Covance). When comparing between experimental groups or across genotypes, slides were processed together, thereby minimizing variability.

Primary antibodies included the following: rabbit anti-cD1 $(\alpha-\mathrm{cD} 1)(1$ : 500; RM-9104; LabVision), mouse $\alpha$-cD2 (1:100; MS-221; LabVision), rabbit $\alpha$-Tbr2 (1:1000; Millipore Corporation), rabbit $\alpha$-cleaved caspase-3 (1: 1000; Millipore Corporation), mouse $\alpha$-Pax-6 (1:400; Developmental Studies Hybridoma Bank), rabbit $\alpha$-Ki67 (1:1000; SP6; LabVision), mouse anti-bromodeoxyuridine (BrdU) (1:50; GE Healthcare), mouse $\alpha$-p27 (1:10,000; Sigma-Aldrich), rabbit $\alpha$-phosphorylated retinoblastoma ( $\mathrm{pRb}$ ) (1:200; Cell Signaling Technology), rabbit $\alpha$-phosphohistone 3 (PH3) (1:1000; Millipore Corporation), mouse $\alpha$-reelin (1:500; Millipore Corporation), rabbit $\alpha$-Tbr1 (1:2000; courtesy of Robert F. Hevner, University of Washington, Seattle, WA), mouse $\alpha$-Tuj1 ( $\beta$-III tubulin; 1:2000; Covance), and mouse $\alpha$-neuronal-specific nuclear protein (NeuN) (1:5000; Millipore Corporation). A terminal deoxynucleotidyl transferase-mediated biotinylated UTP nick end labeling (TUNEL) kit (S7101; Millipore Corporation) was used for in situ labeling of nuclei with DNA strand breaks. The specificity of the $\alpha$-cD2 and $\alpha$-cD1 antibodies used here has been established previously (Glickstein et al., 2007a).

For dual labeling, standard reaction for $\mathrm{cD} 1$ or $\mathrm{cD} 2$ immunoperoxidase labeling was followed by Sniper block and incubation with primary antibodies against Tbr2 or Pax 6 at $+4^{\circ} \mathrm{C}$ overnight. After washing, sections were incubated in Alexa Fluor-conjugated secondary antibodies (1:500; Invitrogen) for $1 \mathrm{~h}$, washed, and coverslipped with Vectashield (Vector Laboratories). At least 20 tissue sections from multiple embryos were examined to confirm or refute the coexpression of cDs with Pax6 or Tbr2 at E12.5, E14.5, and E16.5. Images of DAB-labeled nuclei were inverted and pseudocolored and subsequently overlaid with immunofluorescent images. Antibodies for $\mathrm{BrdU}$ and Tbr2, PH3, or Ki67 were combined for traditional dual-immunofluorescent labeling. Fluorescently labeled sections were counterstained with $4^{\prime}, 6^{\prime}$-diamidino-2-phenylindole (DAPI) (Vector Laboratories) and immunoperoxidase-only labeled sections were counterstained with hematoxylin. Sections were photographed digitally at $4 \times, 10 \times$, and $20 \times$ magnification using a SPOT camera (Diagnostic Instruments). Images were not modified in any way, except for adjustments of brightness and contrast.

\section{BrdU pulse labeling}

BrdU was administered $(50 \mathrm{mg} / \mathrm{kg}$, i.p.) to pregnant mice 1 or $24 \mathrm{~h}$ before harvest date to assess the S-phase labeling index and the proliferative fraction, respectively, as enumerated in Results. A cumulative BrdU labeling protocol was followed to determine the growth fraction (GF) (fraction of the cell population that is proliferative), to determine the time to reach the growth fraction $\left(\mathrm{T}_{\mathrm{c}}-\mathrm{T}_{\mathrm{s}}\right)$, and, subsequently, to estimate the length of the cell cycle $\left(\mathrm{T}_{\mathrm{c}}\right)$ and the duration of S-phase $\left(\mathrm{T}_{\mathrm{s}}\right)$ and $\mathrm{G}_{1}$-phase $\left(\mathrm{T}_{\mathrm{Gl}}\right)$ (Takahashi et al., 1995a). Pregnant mice were injected with $\mathrm{BrdU}(50 \mathrm{mg} / \mathrm{kg}$, i.p.) starting at E14.5-E15 with survival times of 0.5 and $3.5 \mathrm{~h}$ (after single injection at $t=0 \mathrm{~h}$ ), 6.5 and $9.5 \mathrm{~h}$ (after doses at $t=0,3 \mathrm{~h}$ ), 12.5 and $15.5 \mathrm{~h}$ (after doses at $t=0,3,6 \mathrm{~h}$ ), and $18 \mathrm{~h}$ (after doses at $t=0,3,6,9 \mathrm{~h}$ ). Other mice were killed at $1.5,2$, and $2.5 \mathrm{~h}$ after BrdU injection to estimate the duration of $\mathrm{G}_{2}-\mathrm{M}$-phase $\left(\mathrm{T}_{\mathrm{G} 2+\mathrm{M}}\right)$.

\section{Quantification of cell cycle dynamics and statistics}

All quantification was performed blind to genotype and using a standard field of view that consisted of $100 \mu \mathrm{m}$ linear distance of the dorsomedial cortex at the mid-hemispheric level. Three fields of view for each case were averaged, and all groups contained sets of WT and null littermates 




Figure 3. Evidence that $C D 2$ functions in cortical progenitors transitioning from radial glia into IPCS. $A-E$, Pax-6- and Tbr2-immunofluorescent cell numbers are significantly reduced in $C D 2^{-/-}$ (A) compared with $\mathrm{CD}^{+/+}$mice $(\boldsymbol{B})$ and are equivalent in $\mathrm{CD} 1^{+/+}(\boldsymbol{C})$ and $\mathrm{CD} 1^{-/-}(\boldsymbol{D})$ littermates. $\boldsymbol{E}$, Quantification of $\mathrm{Pax} 6^{+}, \mathrm{Tbr}^{+}{ }^{+}$, and dual-labeled Pax $6^{+} / \mathrm{Tbr} 2^{+}$cell numbers in the E14.5 neuroepithelium. ${ }^{*} p<0.05$. NS, Not significant. $\boldsymbol{F}$, Proportion of Pax6, Tbr2 single, and dual-labeled cells in E14.5 neuroepithelium. $n=4-5$ embryos per group. $\boldsymbol{G}$, The number of intermediate progenitors, identified as Tbr2 cells dual immunolabeled with BrdU immunoreactivity (BrdU-IR; administered 3.5 and $6.5 \mathrm{~h}$ before harvest) is significantly reduced in $C D 2^{-/-}$compared with $C D 2^{+/+}$and $\mathrm{CD}^{+/+}$and unchanged in $\mathrm{CD} 1^{-/-}$mice. $\boldsymbol{H}-\boldsymbol{K}$, Appearance of anti-CD2 immunostaining $(\alpha-\mathrm{CD} 2)$ in control $(\boldsymbol{H}, \boldsymbol{J})$ and Tbr2-CKO $(\boldsymbol{I}, \boldsymbol{K})$ embryonic cortex at E13 and E14.5. $\boldsymbol{L}$, Relative timing of Pax6, CD2, and Tbr2 expression based on results in Figures 2 and 3 . CD2 spans the temporal progression of cortical progenitors from Pax6 to Tbr2 expression, as cells transition from radial glial cells to intermediate progenitors. Tbr2 expression continues beyond CD2, because CD2 is detected only in proliferative cells (Glickstein et al., 2007a) and Tbr2 persists briefly in postmitotic progenitors (Hevner et al., 2006).

(tissues from three or more litters were examined for each parameter). Genotype averages were compared using a Student's $t$ test $(p<0.05$ level of significance). As detailed below, some quantification paradigms used SVZ-located PH3-labeled nuclei to define the abventricular limit of the VZ equivalently in all genotypes.

Distribution of PH3-labeled nuclei. PH3-immunopositive nuclei were counted in the VZ (those at the ventricular wall) or SVZ (those labeled cells positioned abventricularly, typically $>70 \mu \mathrm{m}$ from ventricle).

S-phase labeling index. Tissues were labeled for BrdU and PH3 dualimmunofluorescence. The fraction of DAPI-labeled cells having BrdU labeling ( $1 \mathrm{~h}$ after BrdU application) was calculated for the VZ (ventricular wall to the diameter of one cell ventral to $\mathrm{PH} 3$-labeled cells) or the SVZ (tissue above the VZ).

Proliferative fraction. Determined $24 \mathrm{~h}$ after BrdU injection, this was the fraction of BrdU-positive cells that dual immunolabel for Ki67. Thus, the "in-cycle fraction" represents the cells that remain in the cell cycle over a $24 \mathrm{~h}$ period after BrdU pulse.

The quiescent fraction. The reciprocal of the in-cycle fraction, the "cycle-exited fraction" evaluates the cells labeled with BrdU only and not Ki67 and represents the proportion of cells leaving the cycle over a $24 \mathrm{~h}$ period after BrdU injection.

Cell cycle duration. The average fraction of Nissl-labeled cells having BrdU labeling in the VZ (as defined above using PH3 labeling) was calculated for each group/genotype, and the linear least squares algorithm for linear regression analysis (Excel; Microsoft) was performed to estimate $\mathrm{T}_{\mathrm{c}}-\mathrm{T}_{\mathrm{s}}$ and $\mathrm{T}_{\mathrm{s}}$ for each genotype. This analysis was performed as described in detail previously (Takahashi et al., 1993, 1995a; Lu et al., 2007). The fraction of PH3-labeled cells having BrdU labeling in the VZ in dual-labeled sections was calculated, and the least squares algorithm was used to estimate $T_{G 2+M}$. $T_{G 1}$ was then deduced, and estimates of $T_{c}$, $\mathrm{T}_{\mathrm{s}}, \mathrm{T}_{\mathrm{G} 1}$, and $\mathrm{T}_{\mathrm{G} 2+\mathrm{M}}$ and their SEs [ $\mathrm{T}_{\mathrm{G} 1}$ SE estimated as described previously (Lu et al., 2007)] were statistically compared using a $Z$-test statistic (significance at $p<0.05$ if $Z>1.96$ on two-sided test). Cell cycle parameters estimated here were in line with those reported previously for C57BL/6J mice (Hodge et al., 2004; Chakrabarti et al., 2007).

Proportion of Tbr2-immunopositive cells labeled with BrdU. Tissue from the cumulative BrdU labeling experiment (pulses at $t=0,3 \mathrm{~h}$ and harvest at $t=6.5 \mathrm{~h}$ ) was labeled for BrdU and Tbr2 dual immunofluorescence. The fraction of all Tbr2-labeled cells having BrdU labeling was calculated.

Quantification of Tbr2- and Pax6-labeled cells. Single- and dual-labeled nuclei were counted in Tbr2 and Pax6 dual-immunofluorescently labeled tissue sections in a field of view that consisted of $50 \mu \mathrm{m}$ linear distance of the dorsomedial cortex at the mid-hemispheric level in three sections per subject, which were then averaged for each case.

\section{Quantitative stereology}

Two-dimensional and stereological counting methods were used to estimate neuron numbers and density in adult $c D 2^{-/-}, c D 1^{-/-}$, and $\mathrm{WT}$ 
littermates using the optical fractionator (West et al., 1991) and Stereoinvestigator software (MicroBrightField). Nissl-labeled neurons in the somatosensory barrel field cortex of $40 \mu \mathrm{m}$ sections (collected from fixed brains using a sliding microtome) were assessed by morphological criteria that characterize neuronal nuclei (Peters et al., 1991) and were counted in superficial (layers II-III) or deep (layers IVVI) cortical layers. The barrel fields were analyzed in one hemisphere for each section in the series in which it was present $(6-8$ sections collected every $200 \mu \mathrm{m}$ ). The barrel fields were easily identifiable by the densely packed cell columns of granule cells in layer IV characteristic of this cortical region and as described previously (Glickstein et al., 2005). The medial and lateral limits included only those regions of somatosensory cortex having clearly visible barrels. Optical dissector frame and counting grid sizes of 30 and $250 \mu \mathrm{m}^{2}$, respectively, permitted systematic random sampling of three to five neurons within an $8 \mu \mathrm{m}$ depth focusing range for each sampling field and $>200$ total neurons for each subregion per case. Intrasample coefficients of error (Schmitz and Hof, 2000 ) were always $<0.05$ and were equivalent across genotypes. All regions were sampled at $63 \times$ magnification in Koehler illumination conditions. The volume of the different laminar domains of interest in each subregion was estimated using the Cavalieri principle. The estimated total neuron numbers were expressed as the density per subregion, thereby controlling for the reduced brain volume in $c D 2^{-1-}$ mice. $c D 2^{-/-}$and $c D 2^{+/+}$littermates (from three litters) were examined in adulthood $\left(8-10\right.$ weeks) and $c D 1^{-/-}$and $c D 1^{+/+}$littermates (from four litters) were examined at postnatal day 21 attributable to premature death of $c D 1^{-1-}$ mice thought to be a result of starvation (Sicinski et al., 1995). In WT mice, the average barrel field volumes were $1.58 \pm$ $0.05 \mathrm{~mm}^{3}$ (8-10 weeks) and $1.50 \pm 0.14 \mathrm{~mm}^{3}$ (3 weeks), and the average estimated number of neurons was $2.73 \times 10^{5} \pm 1.8 \times 10^{4}(8-10$ weeks) and $2.67 \times 10^{5} \pm 2.6 \times 10^{4}$ ( 3 weeks). The diameters of 20 randomly selected neurons per case were measured to compare neuronal size between genotypes, and no differences in neuronal diameter between genotypes in any group were detected. Genotype averages were compared using a Student's $t$ test $(p<0.05)$.
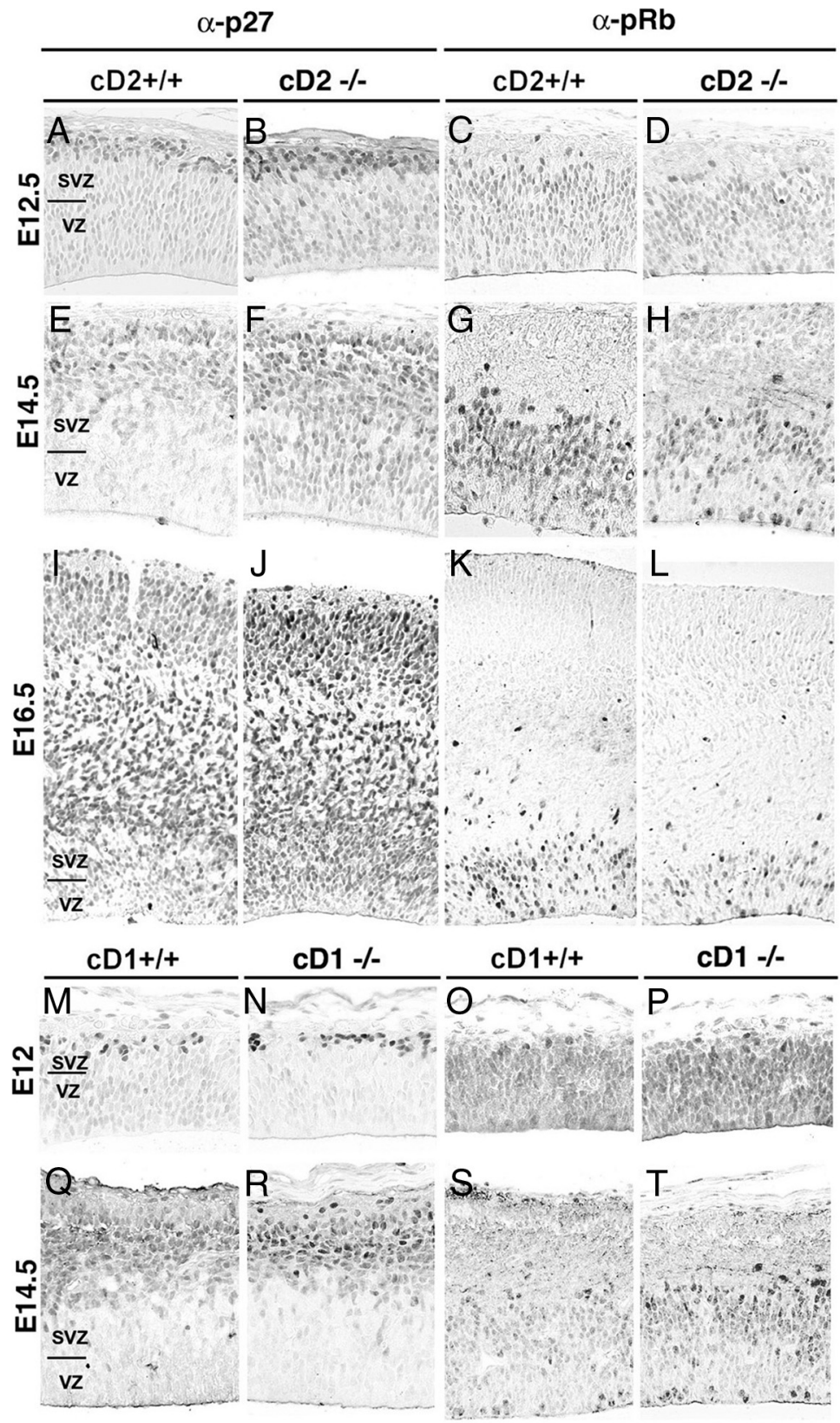

Figure 4. Cdk-inhibitor p27 and $C D$-Cdk effector retinoblastoma (pRb) in the cortex of $\mathrm{CD2}^{-/-}$and $\mathrm{CD}^{-/-}$mice and WT littermates. $A-L$, The labeling intensity of $p 27$ is increased in $C D 2^{-/-}$mice $(B, F, J)$ compared with $C D 2^{+/+}(A, E, I)$ at early and later ages in the neurogenic period. Nuclei immunostained for $\mathrm{pRb}$ were diminished in abventricular cortical regions in $\mathrm{CD}^{-/-}$ $(\boldsymbol{D}, \boldsymbol{H}, \boldsymbol{L})$ relative to $C D 2^{+/+}(C, G, K)$ across the neurogenic period. $M-T, I$ mmunolabeling for 27 was paler in the ventricular zone of $C D 1^{-1-}(\boldsymbol{N}, \boldsymbol{R})$ compared with WT $(M, \mathbf{Q})$ at all ages examined. Labeling for pRb was unchanged in $C D 1^{-/-}(\boldsymbol{P}, \boldsymbol{T})$ compared with WT $(\mathbf{O}, \mathbf{S})$. Labeling was examined in three to five cases per genotype.

\section{Results}

\section{Aberrant development of cyclin D2 $\left(c D 2^{-/-}\right)$but not cyclin} D1 $\left(c D 1^{-/-}\right)$null neocortex

Developmental defects in mice deficient for cD2 result in microcephaly and selective parvalbumin interneuron deficits in forebrain and cerebellum (Huard et al., 1999; Glickstein et al., 2007b). In contrast, mice lacking cD1 are normocephalic and have no interneuronopathies (Chen et al., 2005; Glickstein et al., 2007b). The volume and neuronal packing density within the somatosensory barrel field cortex was stereologically analyzed in $c D 2^{-/-}, c D 1^{-/-}$, and WT littermates. The cortex was thinner in $c D 2^{-/-}$mice compared with $c D 2^{+/+}$(Fig. $1 A, B$ ), and volume reductions were greater in the superficial $(\downarrow 42 \%)$ than in the deeper $(\downarrow 31 \%)$ cortical layers (Fig. $1 E$ ). In contrast, the volume of $c D 1^{-/-}$barrel field cortex was only modestly reduced with no exceptional shrinkage in superficial cortical layers (Fig. $1 C-E$ ). Neuronal packing density was comparable in $c D 2^{-1-}$ and $c D 2^{+/+}$; therefore, glutamatergic neuron numbers must be diminished to account for the loss in volume in $\mathrm{cD} 2$ nulls, because they make up the great majority of cortical neurons. Interneurons make up only a small fraction of the cortical cell population, and interneuron loss alone would not be sufficient to account for a marked cortical volume reduction (Glickstein et al., 2007b). In contrast, neuronal packing density in $c \mathrm{Dl}^{-/-}$was mildly elevated relative to $c D 1^{+/+}$mice (Fig. $1 F$ ). Therefore, although $\mathrm{cD} 1$ loss 


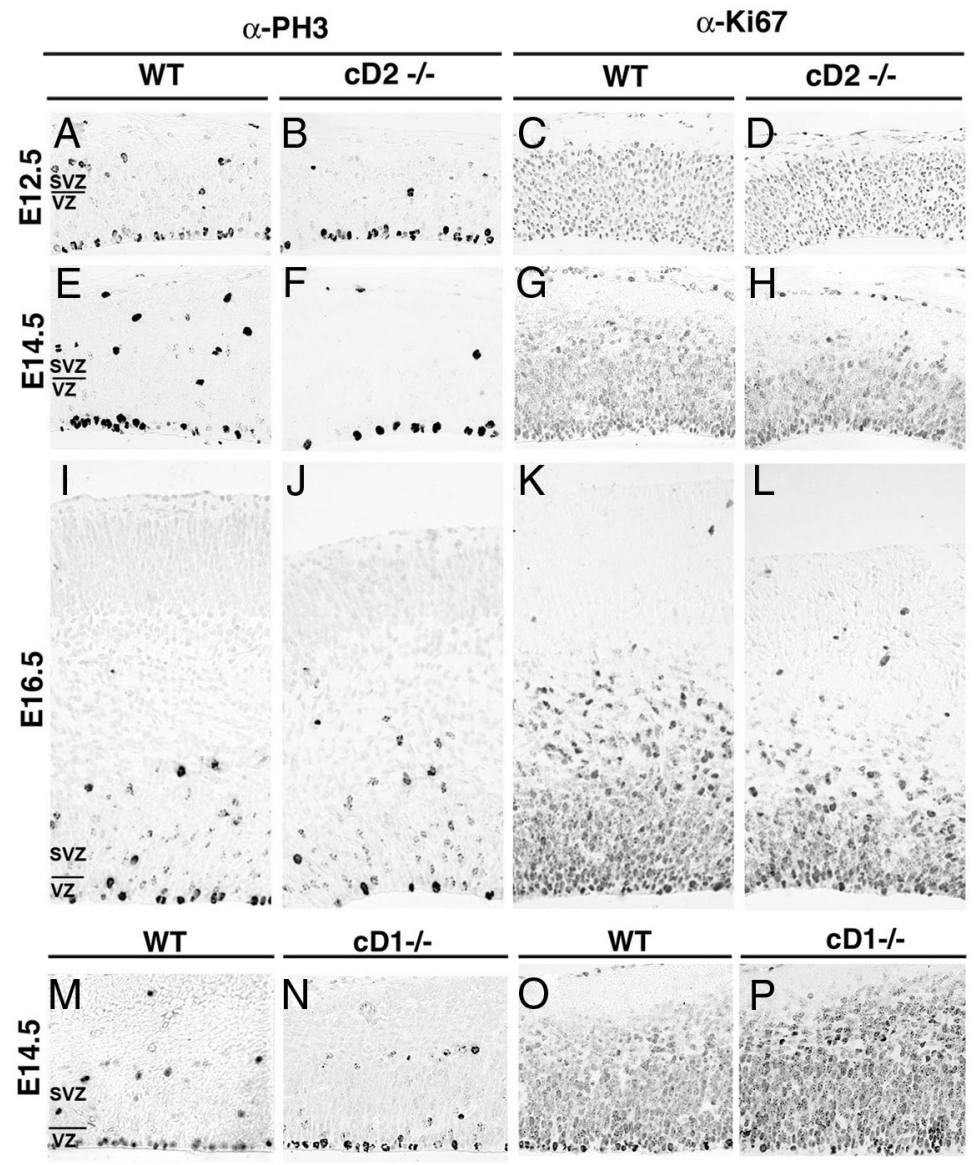

Figure 5. Proliferation markers $\mathrm{PH} 3$ and Ki67 are altered in the cortex of $\mathrm{CD2}^{-/-}$relative to $C D 1^{-/-}$and WT littermates. $A-\boldsymbol{L}$, The numbers of PH3-labeled $\mathrm{M}$-phase nuclei are reduced in the SVZ but unchanged in the VZ of $\mathrm{CD}^{-/-}(B, F, J)$ compared with ${ }_{C D 2}{ }^{+/+}(A, E, I)$ at E12.5 and E14.5 but not at E16.5. Numbers of Ki67-labeled cells (S-G $G_{2}-M-$ phases) are also reduced in the SVZ of $\mathrm{CD}^{-/-}(\boldsymbol{D}, \boldsymbol{H}, \boldsymbol{L})$ compared with $\mathrm{CD}^{+/+}$littermates $(\boldsymbol{C}, \boldsymbol{G}, \boldsymbol{K})$ across the neurogenic period. $\boldsymbol{M}-\boldsymbol{P}$, The numbers of $\mathrm{PH} 3-$ and Ki67-immunolabeled nuclei are unchanged in $\mathrm{CD}^{-/-}$mice $(\boldsymbol{N}, \boldsymbol{P})$ compared with $\mathrm{CD}^{+/+}(\mathbf{M}, \mathbf{0})$. Labeling was compared in three or more cases per genotype.

was primarily compensated for developmentally, cD2 deficiency was not. Moreover, the considerable deficit in superficial cortical layers suggested that $\mathrm{cD} 2$ was needed to maintain the progenitor pool and/or support later neurogenic events.

\section{Selectively disturbed cell cycle regulation in $c D 2^{-/-}$ embryonic neocortex}

Cyclins D1 and D2 have distinct expression patterns in the embryonic forebrain with limited overlap (Glickstein et al., 2007a). Across the neurogenic period, cD1 cells were mainly localized to the $\mathrm{VZ}$, whereas $\mathrm{CD}$ 2-labeled cells were more prevalent in the SVZ (Fig. $2 A-F)$. In $c D 2^{-/-}$mice, there were fewer $c D 1-$ immunoreactive nuclei abventricularly with paler labeling of nuclei at the ventricular wall (Fig. $2 B$ ). In $c D 1^{-/-}$cortex, the distribution of $\mathrm{cD} 2$-labeled nuclei was more extensive in the $\mathrm{VZ}$ relative to that observed in $c D 1^{+/+}$(Fig. $2 E$ ). In WT, these labeling patterns were consistent in nearly all cortical regions except rostromedial (nascent cingulate) cortex, in which the SVZ is less distinct at this age and $\mathrm{cD} 2$ immunoreactivity was less apparent. Because of the SVZ-biased expression pattern of $\mathrm{cD} 2$, the remaining analyses were focused on the E14.5 dorsomedial cortex (midhemispheric level), in which the SVZ is well established, although other times in the neurogenic period were examined as noted.
Cortical progenitor specification toward glutamatergic neurons proceeds from Pax6 to Tbr2 expression (Hevner et al., 2006; Quinn et al., 2007). In the developing cortex, Pax6-expressing radial glia can divide asymmetrically to yield an RGC and an early SVZ progenitor, which is thought to undergo terminal symmetric division (Noctor et al., 2004; Götz and Barde, 2005; Noctor et al., 2008). The transition to intermediate progenitor (transit amplifying) cells is characterized by dwindling expression of Pax6 and burgeoning expression of Tbr2 (Englund et al., 2005; Hodge et al., 2008; Pontious et al., 2008). There is not an abrupt switch from $\mathrm{Pax}^{+}$to $\mathrm{Tbr}^{+}$expression but rather a gradient, with a subset of cells producing both Pax6 and Tbr2 simultaneously. This may account for why conditional inactivation of Tbr2 starting at E9.5 affects both superficial and deep cortical layers, although outer layers are more severely affected (Sessa et al., 2008). Nuclei expressing $\mathrm{cD} 2$, but not $\mathrm{cD} 1$, also expressed Tbr2 (Fig. 2G-L), indicating that CD2 was selectively used in IPCs. Both cD2 and CD1 immunolabeling overlapped with Pax6 immunofluorescence (Fig. 2M$R$ ), which allowed for both $\mathrm{cDs}$ to have a role in radial glia. Alternatively, $\mathrm{cD} 2$ and Pax6 dual-labeled nuclei might represent cells that were about to or had just become intermediate progenitors, which themselves comprise a minority of cells in the VZ (Hevner et al., 2006; Noctor et al., 2008). Whether nuclei in transition (i.e., those that coexpressed Pax6 and Tbr2) selectively used cD2 was explored, but conclusions regarding triple labeling could not be drawn because of the transient nature of cyclin expression (Sherr, 1994; Sakaue-Sawano et al., 2008) and confidence in the detection of slight immunoreactivity. Notably, no cD1 and Tbr2 colabeled nuclei were observed in $\mathrm{CD} 2^{-/-}$mice (supplemental Fig. 1, available at www.jneurosci.org as supplemental material), which suggested that $\mathrm{cD} 1$ could not compensate for $\mathrm{CD} 2$ in intermediate progenitor cell cycling.

Although their population was reduced, $\mathrm{cD} 2$ was not an absolute requirement for the emergence of glutamatergic neurons, which were present in the cortices of $\mathrm{cD} 2$ mutants. However, in E14.5 cortical neuroepithelium lacking cD2, numbers of Pax6 ${ }^{+}$, Tbr $2^{+}$, and Pax6/Tbr2 dual-labeled cells were significantly reduced compared with wild type (Fig. $3 A, B, E$ ) (supplemental Fig. 2 , available at www.jneurosci.org as supplemental material). In contrast, embryonic cortex lacking $\mathrm{CD} 1$ showed no reduction and indeed tended toward increased numbers of $\mathrm{Pax}^{+}, \mathrm{Tbr} 2^{+}$, or Pax6/Tbr2-labeled cells compared with normal siblings (Fig. $3 C-E)$. Despite the differences in cell numbers in the $c D 2^{-1-}$ embryos, the proportions of Pax6 ${ }^{+}, \mathrm{Tbr}^{+}{ }^{+}$, and Pax6/Tbr2 duallabeled cells were essentially the same in wild-type, $c D 2^{-/-}$, and $c D 1^{-/-}$brains (Fig. $3 F$ ) and compared well with the distribution observed previously in wild-type mice (Englund et al., 2005). Therefore, loss of $\mathrm{cD} 2$ reduces $\mathrm{Pax} 6^{+}, \mathrm{Pax}^{+} / \mathrm{Tbr} 2^{+}$dual- 


\section{A Distribution of Mitotic Figures}

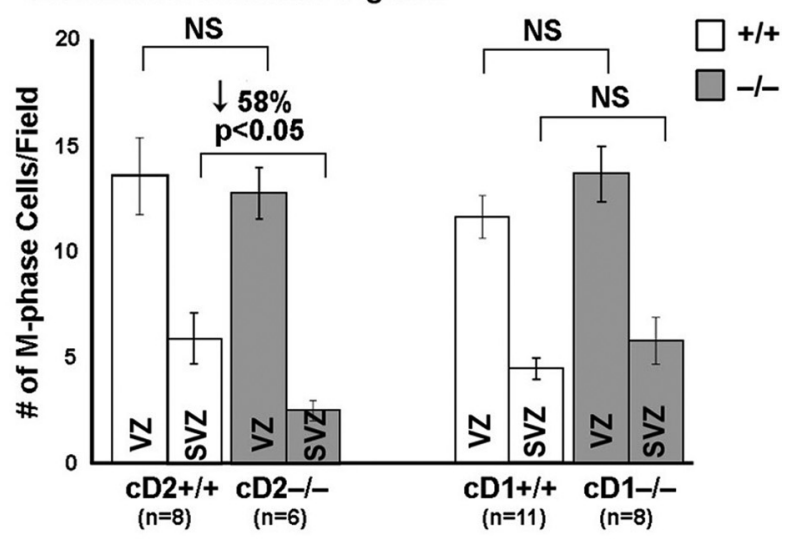

B BrdU Labeling Index

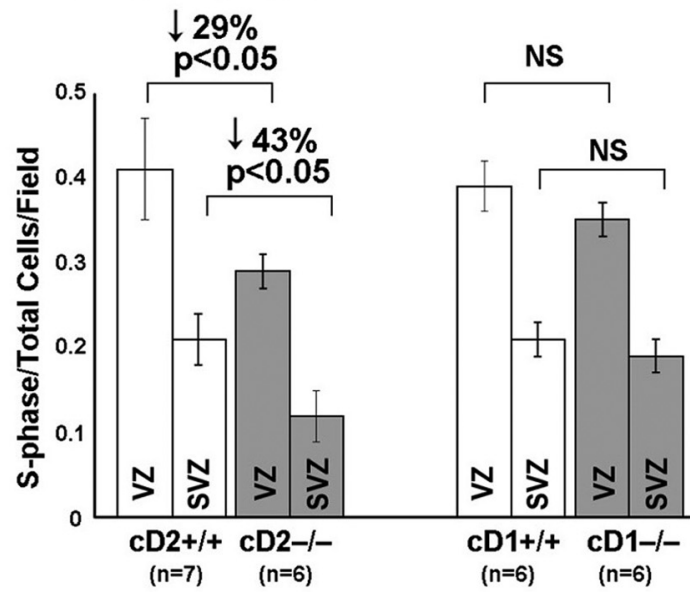

C Proliferative Fraction

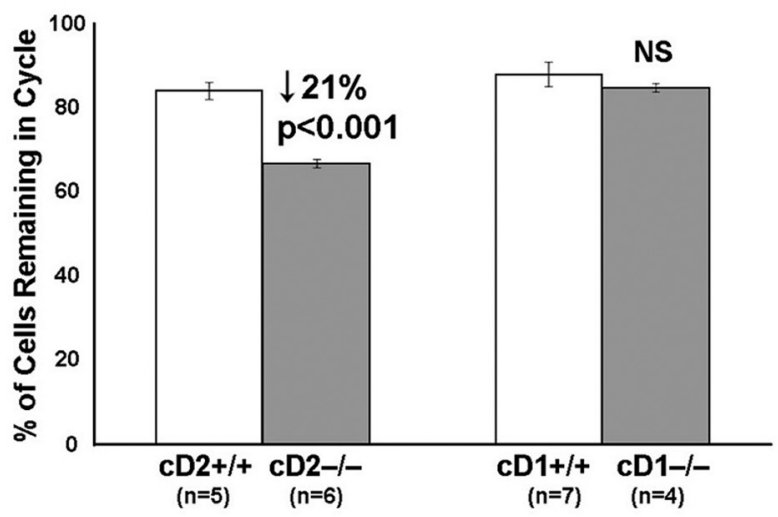

Figure 6. Reduced proliferation and early progenitor cell cycle exit is observed in $\mathrm{CD}^{-/-}$cortex at E14.5. A, Fewer M-phase (PH3-immunopositive) nuclei in the SVZ but not the VZ of $\mathrm{CD}^{-/-}$compared with $\mathrm{CD}^{+/+}$. Equivalent numbers of $\mathrm{M}$-phase nuclei are in the $\mathrm{VZ}$ and $\mathrm{SVZ}$ of $C D 1^{+/+}$and $C D 1^{-/-}$mice. $B$, BrdU $(1 \mathrm{~h})$ pulse labels fewer $S$-phase nuclei in $C D 2^{-/-}$mice. The proportion of total (DAPI) nuclei labeled by anti-BrdU is significantly reduced in the VZ and SVZ of $\mathrm{CD}^{-/-}$compared with $C D 2^{+/+}$mice and is unchanged in $\mathrm{CD1}^{-/-}$. C, Dual immunolabeling with BrdU and Ki67 (to label $S-G_{1}-M$ phase cells) identifies those cells still in cycle $24 \mathrm{~h}$ after the application of BrdU (proliferative fraction). The fraction of dual-labeled cells remaining in cycle is decreased in $\mathrm{CD}^{-/-}$compared with $\mathrm{CD}^{+/+}$mice and is unchanged in $\mathrm{CD}^{-/-}$. This suggests that progenitors are prematurely depleted in $\mathrm{CD}^{-/-}$mice. Field is standard field of view.

labeled, and Tbr $2^{+}$progenitors proportionately, whereas cortical progenitor numbers are unchanged by the loss of cD1 expression. If so, the numbers of intermediate progenitors ( $\mathrm{Tbr} 2^{+}$cells that pulse label with BrdU) should also be diminished in cD2 nulls.
Table 1. Duration of cell cycle phases in the $\mathrm{VZ}$ of $\mathrm{CD2}^{-/-}, \mathrm{CD}^{-/-}$, and WT littermates $\left(\mathrm{CD2}^{+/+}, \mathrm{CD1}^{+/+}\right)$

\begin{tabular}{|c|c|c|c|c|}
\hline & $\begin{array}{l}\mathrm{CD2}^{+/+} \\
(n=37)\end{array}$ & $\begin{array}{l}\mathrm{CD2}^{-/-} \\
(n=38)\end{array}$ & $\begin{array}{l}C^{D} 1^{+/+} \\
(n=38)\end{array}$ & $\begin{array}{l}C D 1^{-/-} \\
(n=36)\end{array}$ \\
\hline GF (\%) & $92.5 \pm 0.3$ & $91.6 \pm 2.1$ & $91.7 \pm 4.0$ & $92.6 \pm 0.7$ \\
\hline $\mathrm{T}_{\mathrm{c}}(\mathrm{h})$ & $22.1 \pm 0.9$ & $23.8 \pm 0.8$ & $22.8 \pm 1.4$ & $23.1 \pm 1.7$ \\
\hline$T_{G 2+M}(h)$ & $2.4 \pm 0.1$ & $2.4 \pm 0.1$ & $2.4 \pm 0.1$ & $2.4 \pm 0.2$ \\
\hline $\mathrm{T}_{\mathrm{G} 1}(\mathrm{~h})$ & $12.2 \pm 0.6$ & $16.5 \pm 0.6^{*}$ & $12.4 \pm 0.9$ & $12.4 \pm 1.1$ \\
\hline $\mathrm{T}_{\mathrm{s}}(\mathrm{h})$ & $7.5 \pm 0.3$ & $4.8 \pm 0.2^{*}$ & $8.0 \pm 0.5$ & $8.3 \pm 0.6$ \\
\hline Model fit: SSR/MSE & $0.275 / 0.001$ & $0.234 / 0.001$ & $0.254 / 0.004$ & $0.253 / 0.006$ \\
\hline
\end{tabular}

Data represent estimated parameter \pm SE. SSR, Sum of squared residuals; MSE, mean squared error. No significant differences between $C D 1^{+/+}$and $C D 1^{-/-}$or $\mathrm{CD2}^{+/+}$estimates. ${ }^{*} p<0.05 ; z$-statistic, $7.98\left(\mathrm{~T}_{\mathrm{s}}\right),-5.1\left(\mathrm{~T}_{\mathrm{G} 1}\right)$ $\mathrm{CD} 2^{+/+}$versus $\mathrm{CD}^{-/-}$

This latter hypothesis was confirmed by significant reductions ( $\downarrow 38 \%)$ in the fraction of Tbr2 cells that dual labeled with BrdU $6.5 \mathrm{~h}$ after the application of BrdU in $c D 2^{-/-}$mice (Fig. $3 G$ ); this pulse duration (two pulses were administered 3.5 and $6.5 \mathrm{~h}$ before harvest) allowed for labeling of transitioning cells.

The proportional loss of Pax $6^{+}$only, Tbr $2^{+}$only, and Pax $6^{+} /$ Tbr2 ${ }^{+}$cells in $\mathrm{cD} 2$ null embryos raises the question as to where cD2 is induced during the temporal progression of cortical progenitor development. Gene expression arrays validated by realtime PCR studies have shown previously that, in the absence of Pax6, E15 mouse cortex displays a twofold induction of cD2 compared with controls (Holm et al., 2007). Thus, Pax6 is not required to induce $\mathrm{cD} 2$ expression in cortical progenitors. We therefore tested whether Tbr2 expression is required for $\mathrm{cD} 2 \mathrm{ex}$ pression to appear in embryonic cortex (Fig. $3 H-K$ ). Conditional inactivation of Tbr2 in Tbr2fx/fx::Foxg1-Cre (Tbr2-CKO) embryonic cortex was compared with littermate Tbr2fx/fx $\left(\mathrm{Tbr} 2^{+/+}\right)$ controls at E13 and E14.5. Immunostaining for $\mathrm{CD} 2$ was equivalent to control at E13 but appeared to label fewer cells in the E14.5 cortex. This cD2 pattern in theTbr2-CKO parallels an enhanced cell cycle exit documented in the conditional Tbr2 mutant (Arnold et al., 2008; Sessa et al., 2008) and suggests an earlier peak in the transitioning population. Diminished CD2 expression in the E14.5 Tbr2-CKO could result if Tbr2 promoted cD2 expression or simply because, as shown previously, by this age, there were fewer basal progenitor cells to express cD2 (Arnold et al., 2008; Sessa et al., 2008). Thus, although it could not distinguish whether Tbr2 has a negative or positive modulatory effect on cD2, the data clearly showed that Tbr2 expression was not required for $\mathrm{cD} 2$ expression in cortical progenitors. Together, the data in Figures 2 and 3 positioned the timing of $\mathrm{cD} 2$ expression in cortical progenitors as they transition from Pax6 ${ }^{+}$RGCs into IPCs (Fig. 3L).

To understand the impact of $\mathrm{cD} 2$ deficiency on the cell cycle, three $G_{1}-S$ regulatory proteins, the cyclin-dependent kinase inhibitors p27-Kip1 and p57-Kip2, and phosphorylated (Ser807/811) retinoblastoma (pRb) were examined in the cortex of $c D 2^{-/-}, c D 1^{-/-}$, and WT littermates (Fig. 4). No p57immunoreactive nuclei were observed in the cortical plate (data not shown), suggesting the importance of p27 in the cortical wall during neurogenesis. Compared with $c D 2^{+/+}$embryos, p27 immunoreactivity was elevated in $c D 2^{-/-}$cortex across the neurogenic period (Fig. $4 A, B, E, F, I, J$ ), whereas p27 was reduced in the SVZ/VZ of $c D 1^{-/-}$embryos compared with $c D 1^{+/+}$or $c D 2^{+/+}$ tissues (Fig. $4 M, N, Q, R)$. pRb immunolabeling was reduced in $c D 2^{-/-}$, most notably in the SVZ (Fig. $4 C, D, G, H, K, L$ ), and unchanged in $c D 1^{-1-}$ (Fig. 4O,P,S,T) from E12.5 through E16.5. The increased expression of $\mathrm{p} 27$ and decreased expression of $\mathrm{pRb}$ in $c D 2^{-/-}$cerebral wall were consistent with slower progression 
Table 2. Summary of $\mathrm{G}_{1}$-modulator expression and cell cycle analyses in $C D 2^{-/-}$and $C D 1^{-/-}$cortex compared with WT littermates

\begin{tabular}{|c|c|c|c|c|c|c|c|c|c|c|}
\hline & $\alpha-\mathrm{CD} 1$ & $\alpha-\mathrm{CD2}$ & $\alpha-\operatorname{Tbr} 2 /$ Pax6 & $\alpha-p 27$ & $\alpha-\mathrm{pRb}$ & \#M-phase & S-phase labeling & In-cycle fraction & Exited-cycle fraction & Cell cycle duration \\
\hline \multicolumn{11}{|l|}{$C D 2^{-1-}$} \\
\hline VZ & $\uparrow$ & & $\downarrow$ & $\uparrow \uparrow$ & $\downarrow$ & $\leftrightarrow$ & $\downarrow$ & $\downarrow \downarrow$ & $\uparrow \uparrow$ & $\uparrow \mathrm{T}_{\mathrm{c}^{\prime}} \uparrow \mathrm{T}_{\mathrm{G} 1}, \downarrow \mathrm{T}_{\mathrm{s}}$ \\
\hline SVZ & $\leftrightarrow$ & & $\downarrow$ & $\uparrow \uparrow$ & $\downarrow$ & $\downarrow$ & $\downarrow \downarrow$ & $\downarrow \downarrow$ & $\uparrow \uparrow$ & $\uparrow \mathrm{T}_{\mathrm{C}^{\prime}} \uparrow \mathrm{T}_{\mathrm{G} 1}, \downarrow \mathrm{T}_{\mathrm{s}}$ \\
\hline \multicolumn{11}{|l|}{$C D 1^{-/-}$} \\
\hline VZ & & $\uparrow \uparrow$ & $\leftrightarrow$ & $\downarrow$ & $\leftrightarrow$ & $\leftrightarrow$ & $\leftrightarrow$ & $\leftrightarrow$ & $\leftrightarrow$ & $\leftrightarrow$ \\
\hline SVZ & & $\uparrow$ & $\leftrightarrow$ & $\leftrightarrow$ & $\leftrightarrow$ & $\leftrightarrow$ & $\leftrightarrow$ & $\leftrightarrow$ & $\leftrightarrow$ & $\leftrightarrow$ \\
\hline
\end{tabular}

through $\mathrm{G}_{1}$-phase in the absence of $\mathrm{cD} 2$. Overexpression or knockdown of $\mathrm{Rb}$ and $\mathrm{p} 27$ has selective effects on cell cycle duration in $\mathrm{G}_{1}$-S-phase and neuron production (Sherr, 2000; Geng et al., 2001; Mitsuhashi et al., 2001; Ferguson et al., 2002). The immunolabeling results presented here indicated that $\mathrm{CD} 1$ and cD2 are poised to differentially regulate cell cycle progression and exert distinct effects on cortical development.

The expression of cell cycle markers was compared in mutant and WT cortex. In $c D 2^{-1-}$ mice, numbers of $\mathrm{PH} 3$-positive, $\mathrm{M}$-phase nuclei were unchanged at the ventricular surface at E12.5, E14.5, and E16.5 but were substantially reduced (as much as $-58 \%$ ) abventricularly at E12.5 and in the SVZ at E14.5 (Figs. $5 A, B, E, F, I, J, 6 A)$. In contrast, $\mathrm{PH} 3$-labeled cell numbers were unaffected in $c D 1^{-1-}$ (Figs. 5M,N, 6A). Ki67 labeling $\left(\mathrm{S}-\mathrm{G}_{2}-\mathrm{M}-\right.$ phase cells) was also reduced abventricularly in $c D 2^{-1-}$ at E12.5, E14.5, and E16.5 (Fig. 5C,D, G,H,K,L) but was mildly increased in $c D 1^{-/-}$(Fig. 5O, $P$ ). Thus, the proliferating progenitor pool was diminished in the $c D 2^{-/-}$cortex, notably in the SVZ. Despite this reduction in the $c D 2^{-/-}$progenitor pool, no qualitative changes with respect to wild-type siblings were observed at these embryonic ages in the distribution of postmitotic cells expressing Tbr1, a transcription factor expressed in glutamatergic neurons (supplemental Fig. 3, available at www.jneurosci.org as supplemental material) or reelin (supplemental Fig. 4, available at www. jneurosci.org as supplemental material), expressed in CajalRetzius neurons. Thus, the output of postmitotic neurons from the neuroepithelium was likely increased in the early-mid neurogenic period. TUNEL and activated caspase- 3 immunolabeling detected no differences in apoptosis among $c D 2^{-/-}, c D 1^{-/-}$, and WT cortices during the neurogenic period (supplemental Fig. 5, available at www.jneurosci.org as supplemental material) or postnatally (Glickstein et al., 2007b).

Cell cycle dynamics were further explored (Fig. 6, Tables 1, 2) (supplemental Tables 1, 2, available at www.jneurosci.org as supplemental material). At E14.5, the number of PH3-labeled, $\mathrm{M}$-phase cells in the VZ did not significantly differ in $c \mathrm{D}^{-/-}$and $c D 1^{-/-}$compared with wild-type siblings (Fig. 6A). However, compared with WT and $c D 1^{-/-}$mice, the number of abventricular M-phase cells was sharply decreased in the cD2 nulls, showing almost $60 \%$ fewer $\mathrm{PH}_{3}{ }^{+}$cells in the SVZ but no significant decrease in VZ mitoses (Fig. 6A). In addition, fewer BrdU pulselabeled, S-phase nuclei ( $1 \mathrm{~h}$ after BrdU administration) were present in both the $\mathrm{VZ}$ and the $\mathrm{SVZ}$ in $\mathrm{CD} 2$ with respect to either wild-type controls or cD1 nulls (Fig. 6B) (supplemental Table 1, available at www.jneurosci.org as supplemental material). Compared with wild type, the S-phase labeling index was reduced more severely in the $c D 2^{-/-}$SVZ than VZ (43 vs 29\%) (Fig. 6B). Therefore, although cell cycle dynamics were affected in both VZ and SVZ compartments of cD2 nulls, the SVZ was more severely impacted by the loss of $\mathrm{cD} 2$ expression.

To explore whether there was an enhanced rate of terminal divisions to account for depletion of the progenitor pool in the $c D 2^{-/-}$cortex, we measured the fraction of $\mathrm{BrdU}^{+}$progenitors expressing Ki67 and therefore remaining in cycle $24 \mathrm{~h}$ after BrdU administration. The in-cycle fraction was reduced in $c D 2^{-/-}$but was unchanged in $\mathrm{CDI}^{-/-}$compared with WT at all times examined (reductions in the in-cycle fraction: E16.5 $\gg$ E12.5, E14.5) (Fig. 6C) (supplemental Table 2, available at www.jneurosci.org as supplemental material). Conversely, the cycle-exited fraction was increased, indicating that more progenitor cells exited the cell cycle in $c D 2^{-1-}$ than in WT or $c D 1^{-1-}$, consistent with premature terminal differentiation of progenitors in the absence of $\mathrm{cD} 2$ but not $\mathrm{cD} 1$. The expression of neuroblast and neuron markers Tuj1 and NeuN, which encroach on the $\mathrm{VZ}$ in $c D 2^{-/-}$compared with WT and $c D 1^{-/-}$, further supported this conclusion (supplemental Fig. 6, available at www.jneurosci.org as supplemental material).

To further examine neocortical cell cycle dynamics in the absence of D2 or D1 cyclins, cell cycle phase durations were analyzed in $\mathrm{cD} 2$ and $\mathrm{cD} 1$ null mutants (Table 1). Measuring the duration of individual phases of the cell cycle is not possible in the SVZ (Takahashi et al., 1995b). However, in the VZ, the length of the cell cycle phases was estimated between E14.5 and E15.5 in $c D 2^{-/-}, c D 1^{-/-}$, and WT using a cumulative BrdU pulse-labeling paradigm (Takahashi et al., 1995a). There were no significant differences in the GF between genotypes, which supported that delayed migration in any genotype did not unduly influence results. The duration of each phase did not significantly differ in $c D 1^{-/-}$compared with $c D 1^{+/+}$or $c D 2^{+/+}$. In contrast, the duration of $\mathrm{G}_{1}\left(\mathrm{~T}_{\mathrm{G} 1}\right)$ was substantially prolonged and the duration of $\mathrm{S}$ phase $\left(\mathrm{T}_{\mathrm{s}}\right)$ was significantly reduced in $c D 2^{-/-}$ tissues (Table 1). As a result, the duration of the cell cycle $\left(\mathrm{T}_{\mathrm{c}}\right)$ was mildly yet nonsignificantly increased in $c D 2^{-/-} \mathrm{VZ}$. The prolonged $\mathrm{G}_{1}$-phase duration (Table 1 ) was consistent with the observation of enhanced cell cycle exit in Figure $6 C$ and supplemental Table 2 (available at www.jneurosci.org as supplemental material), because lengthening of $G_{1}$ has been associated with progenitor exit from the cell cycle (Calegari and Huttner, 2003; Tarui et al., 2005).

\section{cD2 is the predominant cyclin D in the human SVZ}

The SVZ is thought to serve a fundamental role in the massive expansion of the cerebral hemispheres, the development of upper cortical layers, and, potentially, in gyrification in the second trimester of human fetal gestation (Kriegstein et al., 2006). We explored whether $\mathrm{CD} 2$ was also the predominant D-type cyclin in the human SVZ at 19 gestational weeks. At this age, the VZ is marginal with respect to the substantially expanded SVZ, which is bisected into an inner and outer SVZ by incoming fibers (Zecevic et al., 2005) (Fig. 7B,C). cD1 showed scant labeling throughout cerebrum, and the few nuclei observed were always in the inner SVZ (Fig. 7D). In contrast, immunolabeling for $\mathrm{cD} 2$ was robust in both the VZ and the SVZ, in both medial and lateral SVZ and was observed in both the outer and the inner SVZ (inner SVZ $\gg$ outer SVZ) (Fig. 7E). The same areas showing robust cD2 immunoreactivity were colabeled for Tbr2 (Fig. $7 F$ ). cD2 may thus serve an important evolutionary role in brain development, be- 
cause it plays a vital role in the cycling of Tbr2-immunopositive cells that can modulate human brain size (Baala et al., 2007).

\section{Discussion}

Previous histological data show that $\mathrm{cD} 1$ and $\mathrm{CD} 2$ predominate in distinct neuroepithelial populations and that $\mathrm{CD} 2$ localizes to SVZ in which transit-amplifying divisions occur (Glickstein et al., 2007a,b). The present study provides a number of additional insights into D-cyclin regulation of cortical histogenesis. First, it was formerly possible that $\mathrm{CD} 2$ is expressed only in IPCs. The present study shows that $\mathrm{CD} 2$ is expressed as cells transition from RGCs to IPCs. Second, cD1 is not expressed in IPCs. Third, it was formerly possible that no IPC could arise without $\mathrm{cD} 2$. The present study shows that $\mathrm{CD} 2$ is not an absolute requirement for $\mathrm{Tbr} 2^{+} / \mathrm{BrdU}^{+}$IPCs to appear.

Fourth, cD2 is important for the expansion of IPC numbers. The location of cD2 labeling, dual expression with Tbr2, and $\mathrm{cD} 2$-deficit effects on the size of the precursor pool subsets including $\mathrm{Pax}^{+}{ }^{+} /$ Tbr $2^{+}$and $\mathrm{Tbr} 2^{+} / \mathrm{BrdU}^{+}$cells indicate that $\mathrm{CD} 2$ is the D-type cyclin used in these expansive IPC divisions. This assertion is further supported by the degree of microcephaly, greater thinning of superficial cortical layers, and significant reduction in the SVZ population in the $c D 2^{-/-}$compared with cD1 nulls (Figs. 3, 6). The additional loss of $\mathrm{Pax} 6^{+}$progenitors in $\mathrm{CD} 2$ nulls, the continued expression of $\mathrm{cD} 2$ in $\mathrm{Pax6}^{-1-}$ cortex (Holm et al., 2007), and in Tbr $2^{-/-}$cortex (Fig. 3) further localizes cD2 function to cells transitioning between RGCs and IPCs and is consistent with the effect of $\mathrm{cD} 2$ loss on both progenitor pools. It is also consistent with the more pronounced impact of $\mathrm{cD} 2$ loss on IPCs, in which abventricular mitoses are significantly diminished in cD2 null embryonic cortex at E14.5, whereas ventricular mitoses, the majority of which occur in cell cycles that use $\mathrm{CD} 1$, are no different from wild-type siblings. The effect of $\mathrm{cD} 2$ loss on IPCs is no less dramatic than that of Insm1 (insulinoma-associated-1) protein that was reported recently to have a role in expansion of basal progenitors in developing neocortex (Farkas et al., 2008), yet Insm1 inactivation only reduces the $\mathrm{Tbr} 2^{+}$IPC population $\left(\mathrm{Tbr} 2^{+} / \mathrm{PH} 3\right.$ dual-labeled cells across both basal and apical locations) by $\sim 50 \%$ (Farkas et al., 2008). This compares well with our data that IPCs still arise in the absence of cD2 but with a nearly $40 \%$ decrease in Tbr2 ${ }^{+}$/ $\mathrm{BrdU}^{+}$dual-labeled cells. Together, data presented here indicate that $\mathrm{cD} 2$ is not necessary for IPCs to emerge but that $\mathrm{CD} 2$ is used in progenitors as they transition into and expand their IPC numbers.

Fifth, the present manuscript shows that $\mathrm{CD} 2$ regulates not only the length of $\mathrm{G}_{1}$-phase but also influences the length of
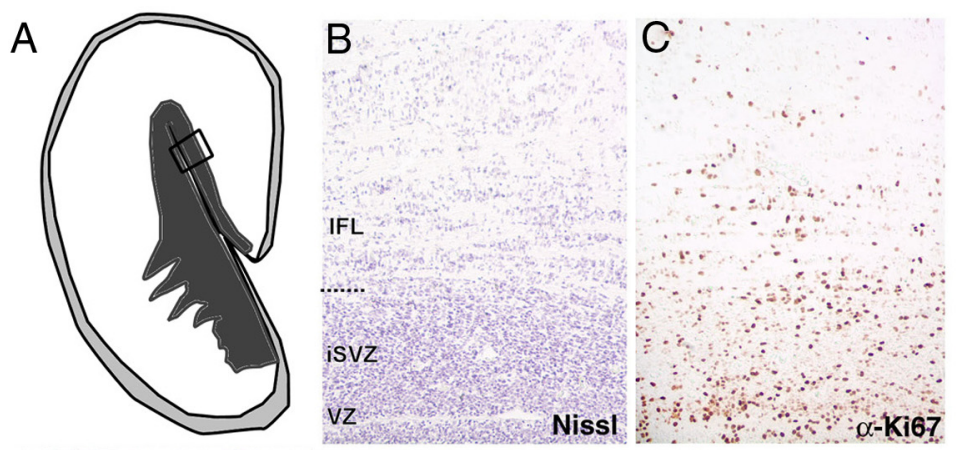

$\mathrm{E}$

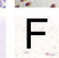

$\mathrm{F}$

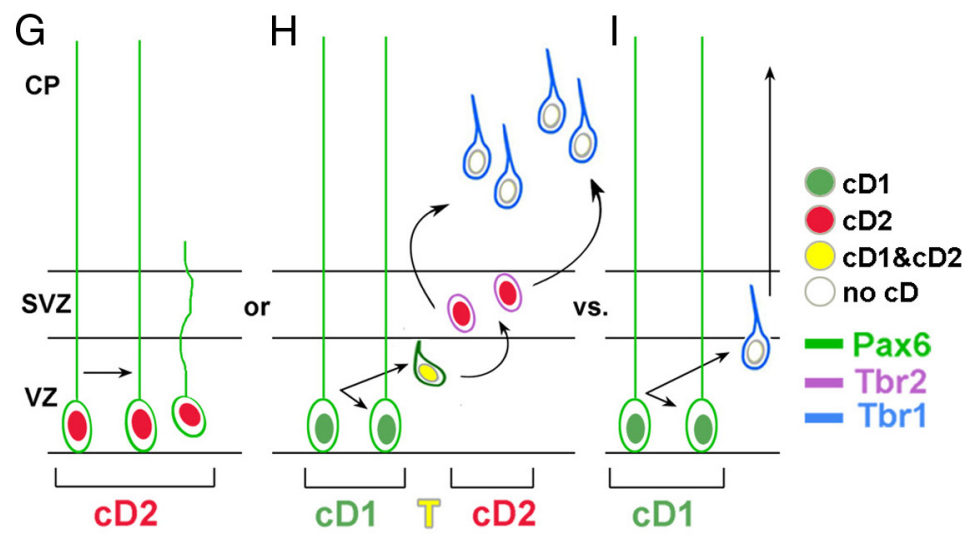

Figure 7. $\quad C D 2$ is the predominant cyclin D in the human SVZ. $\boldsymbol{A}-\boldsymbol{F}$, The proliferative zones of adjacent sections $(10 \mu \mathrm{m})$ of human fetal cortex at 19 gestational weeks shown $(\boldsymbol{B}-\boldsymbol{F})$ are indicated by the box in the schema $(\boldsymbol{A})$. The general architecture of the region is revealed with Niss/ staining $(\boldsymbol{B})$, and the distribution of proliferative cells is discerned with Ki67 immunolabeling (C). Rare nuclei are CD1 immunoreactive (D, arrows), whereas many nuclei are CD2 immunolabeled in both the VZ and the SVZ (E). The distribution of $\mathrm{CD} 2$-immunopositive nuclei overlaps the distribution of Tbr2-immunolabeled cells $(\boldsymbol{F})$. Diagram of $\mathrm{CD} 2$ versus $\mathrm{CD} 1$ usage in embryonic cortex (G-I). Precursor cells label with Pax6 (green cells), Tbr2 (purple cells), or Tbr1 (blue cells). cD2 (red transitioning (yellow nucleus, T) to intermediate progenitors (purple, $\mathrm{Tbr}_{2}{ }^{+}$; red, $\mathrm{CD} 2^{+}$) that divide symmetrically in the SVZ $(\boldsymbol{H})$. n contrast, $C D 1^{+}$radial glial cells undergo asymmetric divisions in the $\mathrm{VZ}$, giving rise to a postmitotic cell (blue, $\mathrm{Tbr}^{+}$) and a renewed radial glial cell $(\boldsymbol{I})$. Note that cells lacking both $\mathrm{CD} 1$ and $\mathrm{CD} 2$ (white nuclei) exit the cycle to become postmitotic, Tbr ${ }^{+}$ (blue) cells. IFL, Inner fiber layer; iSVZ, inner subventricular zone; $C P$, cortical plate.

S-phase $\left(T_{s}\right)$, which has been postulated to be important in the regulation of primate cortex lamination. Sixth, the Tbr2-CKO expresses cD2 even in the absence of Tbr2, suggesting that $\mathrm{cD} 2$ emerges temporally before Tbr2. However, because a smaller population of $\mathrm{Tbr}^{+}$cells still arises in $\mathrm{cD} 2^{-/-}$cortex, there must be $\mathrm{cD} 2$-independent routes to Tbr2 expression, and cD2 is important in cortex primarily to promote the expansion of the IPC pool. Finally, cD2 expression predominates in the human SVZ at 19-20 weeks gestation, supporting a significant role for this protein in the expansion of brain size over the course of species evolution.

Cell cycle parameters estimated here were in line with those reported for C57BL/6J mice (Hodge et al., 2004; Chakrabarti et 
al., 2007) but longer than reported in CD1 mice (Takahashi et al., 1995a). Both estimates of $\mathrm{T}_{\mathrm{G} 2+\mathrm{M}}$ and $\mathrm{T}_{\mathrm{c}}$ were calculated using independent groups within each genotype and were increased to a similar extent ( $\sim 20 \%)$ in both wild-type strains compared with CD1 mice at the same age (Takahashi et al., 1995a). Straindependent factors may account for the longer estimates of cell cycle times in C57BL/6J mice observed here and by others. Regardless of differences in wild-type values compared with the literature, $c D 2^{+/+}$and nulls showed fundamental differences in cell cycle parameters determined in a well controlled study.

The cumulative BrdU labeling experiments were instructive. Despite the relatively small proportion of cD2-expressing cells in the apical progenitor pool, loss of $\mathrm{cD} 2$ expression had a measurable impact on cell cycle dynamics in the VZ. Cell cycle length $\left(\mathrm{T}_{\mathrm{c}}\right)$ tended to be prolonged in the $\mathrm{CD} 2$ nulls but not in $c D 1^{-1-}$ mice. $\mathrm{G}_{1}$-phase $\left(\mathrm{T}_{\mathrm{G} 1}\right)$ was prolonged a striking $4 \mathrm{~h}$ in embryos without $\mathrm{cD} 2$, confirming lack of $\mathrm{cD} 1$ induction in the absence of cD2. Conversely, the unchanged $\mathrm{T}_{\mathrm{G} 1}$ or $\mathrm{T}_{\mathrm{s}}$ in $\mathrm{cD} 1$ nulls supported the effective compensation of $\mathrm{cD} 1$ loss by $\mathrm{cD} 2$ induction. $\mathrm{T}_{\mathrm{G} 1}$ lengthening was consistent with an unopposed increase in expression of the cyclin-dependent kinase (cdk) inhibitor p27, just as acute induction of $\mathrm{p} 27$ prolonged $\mathrm{T}_{\mathrm{G} 1}$ in transgenic mice (Mitsuhashi et al., 2001). However, subsequent direct measurement of cell cycle phases in p27 overexpressors and knock-outs has led to the consensus that modulation of $\mathrm{p} 27$ levels increases the rate of cell cycle exit during neurogenesis without significantly changing $\mathrm{T}_{\mathrm{c}}, \mathrm{T}_{\mathrm{G} 1}$, or $\mathrm{T}_{\mathrm{s}}$ (Tarui et al., 2005). Thus, the observed effect of cD2 loss on $G_{1}$ may result from combinatorial changes in p27, phosphorylated $\mathrm{Rb}$, and/or other cell cycle components yet to be identified. One caveat is that previous data investigating p27 overexpression was gathered between E12 and E14, whereas the present experiments in $\mathrm{CD} 2$ nulls examined the interval between E14.5 and E16, when p27 effects on cell cycle parameters may be more robust. The increased fraction of cells leaving the cycle in $\mathrm{cD} 2$ nulls was consistent with the measured lengthening of $\mathrm{T}_{\mathrm{G} 1}$, because pharmacological inhibition of $\mathrm{G}_{1}$-active cdks prolongs $\mathrm{G}_{1}$, pushing cortical progenitors out of cycle (Calegari and Huttner, 2003; Calegari et al., 2005).

A striking insight from the BrdU cumulative labeling was the contraction of S-phase $\left(T_{s}\right)$ in $c D 2$ nulls. This was unexpected, because $G_{1}$-active $c D 2$ is not known to have effects on S-phase. Loss of cD2 resulted in a "catch up" so that $\mathrm{T}_{\mathrm{c}}$ in the $\mathrm{cD} 2$ nulls was close to wild type. One possible mechanism for shortening of $\mathrm{T}_{s}$ could be that a cyclin E-cdk2 buildup needed to overcome the higher set point created by elevated p27 (unopposed by D-cyclin) served to propel the cell through S-phase, once the $\mathrm{G}_{1}-\mathrm{S}$ checkpoint was traversed. Although immunohistochemical staining for cyclin E was attempted in the cD2 nulls, localization with the available anti-cyclin $\mathrm{E}$ antibodies did not permit a conclusive determination. Similarly, existing phospho-cdk2 antibodies cross react with other cdks (e.g., cdk5). Thus, tests of this hypothesis await more specific/sensitive reagents. Nevertheless, the determination that absence of $\mathrm{cD} 2$ significantly lengthens $\mathrm{T}_{\mathrm{G} 1}$ and shortens $\mathrm{T}_{s}$ in neural progenitors is unique in the examination of cell cycle mouse mutants and suggests that events in both $G_{1}$ - and $\mathrm{S}$-phases may be important to the influence exerted by cD2. Indeed, changes in $T_{s}$ across the period of cortical neurogenesis have been observed in primates, in which biphasic modulation of $\mathrm{T}_{\mathrm{s}}$ has been related to cortical expansion and "laminar elaboration" (Kornack and Rakic, 1998; Dehay and Kennedy, 2007). That $\mathrm{CD} 2$ is the predominant D-cyclin expressed in the human SVZ at 19-20 weeks gestation indicates the evolutionary importance of $\mathrm{cD} 2$ in larger mammals for whom expansive inter- mediate progenitor divisions have been proposed to enable the generation of larger, convoluted, cerebral cortices (Noctor et al., 2008; Pontious et al., 2008). It may be that molecular programs associated with $\mathrm{cD} 2$ allow for changes in $\mathrm{T}_{\mathrm{c}}$ and $\mathrm{T}_{\mathrm{s}}$ sufficient to be detected in $\mathrm{cD} 2$-deficient mouse cortex and that are essential in primate corticogenesis.

These data fit a model in which cyclin D2 is required for expansive cortical cell divisions (Fig. 7G-I). In Pax6-expressing apical progenitors, a relatively small number of cells using cD2 undergo symmetric stem divisions to enlarge the $\mathrm{VZ}$ progenitor pool (Fig. 7G). Asymmetric divisions driven by $\mathrm{CD} 1$ maintain the population by generating a daughter that will leave the $\mathrm{VZ}$ to become a neuron, glial, or intermediate progenitor cell and another daughter that replenishes the radial glial pool (Fig. 7H,I). Cells becoming Tbr2-expressing intermediate progenitors use $\mathrm{cD} 2$ for that critical symmetric transit amplifying division (Fig. $7 H)$. Without either $\mathrm{cD} 1$ or $\mathrm{cD} 2$, progenitors exit the cell cycle and differentiate (Fig. $7 H, I$ ), evident in the increased cell cycle exit in $c D 2^{-1-}$ cortex. The preponderance of $\mathrm{cD} 2$ expression in human embryonic SVZ strongly supports this hypothesized requirement of $\mathrm{cD} 2$ to promote expansive transit amplifying divisions. The fact that double knock-out of $\mathrm{cD} 2$ and $\mathrm{cD} 1$ is not compensated by cD3 expression in brain (Ciemerych et al., 2002) and that cortical neuroepithelial cells still proliferate in the absence of all D-cyclins (Kozar et al., 2004) suggest that cD3 does not play a significant role in either $\mathrm{CD} 2$ or $\mathrm{CD} 1$ null embryonic cortex. The disparity in $\mathrm{CD} 2$ expression between the $\mathrm{VZ}$ and SVZ is consistent with the volume differences between the ventricles and convoluted cortex, and cell number differences from the deep to superficial cortical layers needed to construct a "gyral" brain (Kriegstein et al., 2006; Noctor et al., 2008). Thus, cD2 may be a key evolutionary determinant of cortical size and organization among species.

\section{References}

Arnold SJ, Huang GJ, Cheung AF, Era T, Nishikawa S, Bikoff EK, Molnár Z, Robertson EJ, Groszer M (2008) The T-box transcription factor Eomes/ Tbr2 regulates neurogenesis in the cortical subventricular zone. Genes Dev 22:2479-2484.

Baala L, Briault S, Etchevers HC, Laumonnier F, Natiq A, Amiel J, Boddaert N, Picard C, Sbiti A, Asermouh A, Attié-Bitach T, Encha-Razavi F, Munnich A, Sefiani A, Lyonnet S (2007) Homozygous silencing of T-box transcription factor EOMES leads to microcephaly with polymicrogyria and corpus callosum agenesis. Nat Genet 39:454-456.

Calegari F, Huttner WB (2003) An inhibition of cyclin-dependent kinases that lengthens, but does not arrest, neuroepithelial cell cycle induces premature neurogenesis. J Cell Sci 116:4947-4955.

Calegari F, Haubensak W, Haffner C, Huttner WB (2005) Selective lengthening of the cell cycle in the neurogenic subpopulation of neural progenitor cells during mouse brain development. J Neurosci 25:6533-6538.

Caviness VS Jr, Goto T, Tarui T, Takahashi T, Bhide PG, Nowakowski RS (2003) Cell output, cell cycle duration and neuronal specification: a model of integrated mechanisms of the neocortical proliferative process. Cereb Cortex 13:592-598.

Chakrabarti L, Galdzicki Z, Haydar TF (2007) Defects in embryonic neurogenesis and initial synapse formation in the forebrain of the Ts65Dn mouse model of Down syndrome. J Neurosci 27:11483-11495.

Chen Z, Duan RS, Zhu Y, Folkesson R, Albanese C, Winblad B, Zhu J (2005) Increased cyclin E expression may obviate the role of cyclin D1 during brain development in cyclin D1 knockout mice. J Neurochem 92:1281-1284.

Chenn A, Walsh CA (2003) Increased neuronal production, enlarged forebrains and cytoarchitectural distortions in beta-catenin overexpressing transgenic mice. Cereb Cortex 13:599-606.

Ciemerych MA, Kenney AM, Sicinska E, Kalaszczynska I, Bronson RT, Rowitch DH, Gardner H, Sicinski P (2002) Development of mice expressing a single D-type cyclin. Genes Dev 16:3277-3289. 
Dehay C, Kennedy H (2007) Cell-cycle control and cortical development. Nat Rev Neurosci 8:438-450.

Englund C, Fink A, Lau C, Pham D, Daza RA, Bulfone A, Kowalczyk T, Hevner RF (2005) Pax6, Tbr2, and Tbr1 are expressed sequentially by radial glia, intermediate progenitor cells, and postmitotic neurons in developing neocortex. J Neurosci 25:247-251.

Farkas LM, Haffner C, Giger T, Khaitovich P, Nowick K, Birchmeier C, Pääbo S, Huttner WB (2008) Insulinoma-associated 1 has a panneurogenic role and promotes the generation and expansion of basal progenitors in the developing mouse neocortex. Neuron 60:40-55.

Ferguson KL, Vanderluit JL, Hébert JM, McIntosh WC, Tibbo E, MacLaurin JG, Park DS, Wallace VA, Vooijs M, McConnell SK, Slack RS (2002) Telencephalon-specific Rb knockouts reveal enhanced neurogenesis, survival and abnormal cortical development. EMBO J 21:3337-3346.

Geng Y, Yu Q, Sicinska E, Das M, Bronson RT, Sicinski P (2001) Deletion of the p27Kip1 gene restores normal development in cyclin D1-deficient mice. Proc Natl Acad Sci U S A 98:194-199.

Glickstein SB, Desteno DA, Hof PR, Schmauss C (2005) Mice lacking dopamine D2 and D3 receptors exhibit differential activation of prefrontal cortical neurons during tasks requiring attention. Cereb Cortex 15:1016-1024.

Glickstein SB, Alexander S, Ross ME (2007a) Differences in cyclin d2 and d1 protein expression distinguish forebrain progenitor subsets. Cereb Cortex 17:632-642.

Glickstein SB, Moore H, Slowinska B, Racchumi J, Suh M, Chuhma N, Ross ME (2007b) Selective cortical interneuron and GABA deficits in cyclin D2-null mice. Development 134:4083-4093.

Götz M, Barde YA (2005) Radial glial cells defined and major intermediates between embryonic stem cells and CNS neurons. Neuron 46:369-372.

Hevner RF, Hodge RD, Daza RA, Englund C (2006) Transcription factors in glutamatergic neurogenesis: conserved programs in neocortex, cerebellum, and adult hippocampus. Neurosci Res 55:223-233.

Hodge RD, D'Ercole AJ, O'Kusky JR (2004) Insulin-like growth factor-I accelerates the cell cycle by decreasing $G_{1}$ phase length and increases cell cycle reentry in the embryonic cerebral cortex. J Neurosci 24:10201-10210.

Hodge RD, Kowalczyk TD, Wolf SA, Encinas JM, Rippey C, Enikolopov G, Kempermann G, Hevner RF (2008) Intermediate progenitors in adult hippocampal neurogenesis: Tbr2 expression and coordinate regulation of neuronal output. J Neurosci 28:3707-3717.

Holm PC, Mader MT, Haubst N, Wizenmann A, Sigvardsson M, Götz M (2007) Loss- and gain-of-function analyses reveal targets of Pax6 in the developing mouse telencephalon. Mol Cell Neurosci 34:99-119.

Huard JM, Forster CC, Carter ML, Sicinski P, Ross ME (1999) Cerebellar histogenesis is disturbed in mice lacking cyclin D2. Development 126:1927-1935.

Kornack DR, Rakic P (1998) Changes in cell-cycle kinetics during the development and evolution of primate neocortex. Proc Natl Acad Sci U S A 95:1242-1246.

Kozar K, Ciemerych MA, Rebel VI, Shigematsu H, Zagozdzon A, Sicinska E, Geng Y, Yu Q, Bhattacharya S, Bronson RT, Akashi K, Sicinski P (2004) Mouse development and cell proliferation in the absence of D-cyclins. Cell 118:477-491.

Kriegstein A, Noctor S, Martínez-Cerdeño V (2006) Patterns of neural stem and progenitor cell division may underlie evolutionary cortical expansion. Nat Rev Neurosci 7:883-890.

Levison SW, Goldman JE (1993) Both oligodendrocytes and astrocytes develop from progenitors in the subventricular zone of postnatal rat forebrain. Neuron 10:201-212.

Lu M, Zhang RL, Zhang ZG, Yang JJ, Chopp M (2007) Linkage of cell cycle kinetics between embryonic and adult stroke models: an analytical approach. J Neurosci Methods 161:323-330.

Mitsuhashi T, Aoki Y, Eksioglu YZ, Takahashi T, Bhide PG, Reeves SA, Caviness
VS Jr (2001) Overexpression of p27Kip1 lengthens the G1 phase in a mouse model that targets inducible gene expression to central nervous system progenitor cells. Proc Natl Acad Sci U S A 98:6435-6440.

Noctor SC, Martínez-Cerdeño V, Ivic L, Kriegstein AR (2004) Cortical neurons arise in symmetric and asymmetric division zones and migrate through specific phases. Nat Neurosci 7:136-144.

Noctor SC, Martínez-Cerdeño V, Kriegstein AR (2008) Distinct behaviors of neural stem and progenitor cells underlie cortical neurogenesis. J Comp Neurol 508:28-44.

Peters A, Palay SL, Webster HdF (1991) The fine structure of the nervous system: neurons and their supporting cells, Ed 2. New York: Oxford UP.

Pontious A, Kowalczyk T, Englund C, Hevner RF (2008) Role of intermediate progenitor cells in cerebral cortex development. Dev Neurosci 30:24-32.

Quinn JC, Molinek M, Martynoga BS, Zaki PA, Faedo A, Bulfone A, Hevner RF, West JD, Price DJ (2007) Pax6 controls cerebral cortical cell number by regulating exit from the cell cycle and specifies cortical cell identity by a cell autonomous mechanism. Dev Biol 302:50-65.

Sakaue-Sawano A, Kurokawa H, Morimura T, Hanyu A, Hama H, Osawa H, Kashiwagi S, Fukami K, Miyata T, Miyoshi H, Imamura T, Ogawa M, Masai H, Miyawaki A (2008) Visualizing spatiotemporal dynamics of multicellular cell-cycle progression. Cell 132:487-498.

Schmitz C, Hof PR (2000) Recommendations for straightforward and rigorous methods of counting neurons based on a computer simulation approach. J Chem Neuroanat 20:93-114.

Sessa A, Mao CA, Hadjantonakis AK, Klein WH, Broccoli V (2008) Tbr2 directs conversion of radial glia into basal precursors and guides neuronal amplification by indirect neurogenesis in the developing neocortex. Neuron 60:56-69.

Shen Q, Wang Y, Dimos JT, Fasano CA, Phoenix TN, Lemischka IR, Ivanova NB, Stifani S, Morrisey EE, Temple S (2006) The timing of cortical neurogenesis is encoded within lineages of individual progenitor cells. Nat Neurosci 9:743-751.

Sherr CJ (1994) G1 phase progression: cycling on cue. Cell 79:551-555.

Sherr CJ (2000) The Pezcoller lecture: cancer cell cycles revisited. Cancer Res 60:3689-3695.

Sicinski P, Donaher JL, Parker SB, Li T, Fazeli A, Gardner H, Haslam SZ, Bronson RT, Elledge SJ, Weinberg RA (1995) Cyclin D1 provides a link between development and oncogenesis in the retina and breast. Cell 82:621-630.

Sicinski P, Donaher JL, Geng Y, Parker SB, Gardner H, Park MY, Robker RL, Richards JS, McGinnis LK, Biggers JD, Eppig JJ, Bronson RT, Elledge SJ, Weinberg RA (1996) Cyclin D2 is an FSH-responsive gene involved in gonadal cell proliferation and oncogenesis. Nature 384:470-474.

Takahashi T, Nowakowski RS, Caviness VS Jr (1993) Cell cycle parameters and patterns of nuclear movement in the neocortical proliferative zone of the fetal mouse. J Neurosci 13:820-833.

Takahashi T, Nowakowski RS, Caviness VS Jr (1995a) The cell cycle of the pseudostratified ventricular epithelium of the embryonic murine cerebral wall. J Neurosci 15:6046-6057.

Takahashi T, Nowakowski RS, Caviness VS Jr (1995b) Early ontogeny of the secondary proliferative population of the embryonic murine cerebral wall. J Neurosci 15:6058-6068.

Tarui T, Takahashi T, Nowakowski RS, Hayes NL, Bhide PG, Caviness VS (2005) Overexpression of p27 Kip 1, probability of cell cycle exit, and laminar destination of neocortical neurons. Cereb Cortex 15:1343-1355.

West MJ, Slomianka L, Gundersen HJ (1991) Unbiased stereological estimation of the total number of neurons in thesubdivisions of the rat hippocampus using the optical fractionator. Anat Rec 231:482-497.

Zecevic N, Chen Y, Filipovic R (2005) Contributions of cortical subventricular zone to the development of the human cerebral cortex. J Comp Neurol 491:109-122. 